\title{
Evaluation of an antenatal acupuncture intervention as an adjunct therapy for antenatal depression (AcuAnteDep): study protocol for a pragmatic randomised controlled trial
}

\author{
Simone M. Ormsby ${ }^{1 *}$, Caroline A. Smith², Hannah G. Dahlen³ ${ }^{3}$ Phillipa J. Hay ${ }^{4}$ and Joanne M. Lind ${ }^{5}$
}

\begin{abstract}
Background: Depressed pregnant women face difficulty navigating a course between the potentially serious consequences of leaving depression untreated and significant limitations associated with conventional therapies, such as foetal toxicity and teratogenicity. Preliminary evidence is suggestive that acupuncture may provide a safe and effective alternative treatment option for antenatal depression; however, additional research is required. The purpose of this study is to further investigate this treatment possibility, with an additional examination of a potential biomechanistic acupuncture effect.

Methods/design: In this pragmatic randomised controlled trial, we will compare individually tailored, flexible antenatal depression-oriented acupuncture with equivalent attention progressive muscle relaxation and routine antenatal depression hospital care. Eligible women at 24 weeks of gestation with Edinburgh Postnatal Depression Scale scores of 13 or more will be recruited from 2 antenatal clinics in South Western Sydney, Australia. The recruitment goal of 96 is powered to demonstrate a significant difference in Edinburgh Postnatal Depression Scale score severity between acupuncture and usual care, with intervention groups receiving weekly 1-h treatments for 8 weeks from 24 to 31 weeks of gestation. Mental health and quality-of-life assessments will occur at study commencement, intervention weeks 4 and 8 and 6 weeks post-natally via the collection of completed Edinburgh Postnatal Depression Scale scores, Depression, Stress and Anxiety Scale scores and World Health Organisation Quality of Life Scale scores. Adjustment to mothering will also be evaluated at 6 weeks post-natally using the Being a Mother Scale. A putative biomechanistic effect of acupuncture on the oxytocinergic system will additionally be examined by comparing baseline salivary hormone levels with those measured at intervention weeks 4 and 8, as well as leucocyte oxytocin receptor expression at baseline and intervention week 8.
\end{abstract}

Discussion: Ethical approval was received in February 2015, and recruitment is underway and expected to be completed in July 2016.

Trial registration: Australian New Zealand Clinical Trials Registry ACTRN12615000250538, Registered on 19 March 2015.

Keywords: Acupuncture, Antenatal depression, Intervention, Pragmatic, Protocol, Randomised controlled trial

\footnotetext{
* Correspondence: simone.ormsby@westernsydney.edu.au

${ }^{1}$ PhD Candidate, National Institute of Complementary Medicine, Western

Sydney University, Building 5, Campbelltown Campus, Locked Bag 1797,

Penrith, NSW 2751, Australia

Full list of author information is available at the end of the article
} 


\section{Background}

In developed countries, including Australia, depression in pregnancy occurs at rates similar to those seen in non-pregnant women $[1,2]$, with prevalence reportedly ranging from $7.4 \%$ [3] to $25 \%$ [4] or higher [1] in vulnerable at risk groups [1, 4]. Whilst areas of lower socioeconomic status (SES) have not been identified as a risk factor in all studies [5], they have been shown to contribute to the presence of a greater number of individual psychosocial risks [6] and consequently may result in increased vulnerability. Morbid consequences include a significantly increased risk of obstetric complications $[1,4,7-11]$ and post-natal depression in mothers [2, 12], as well as alterations in growth, development [11, 13], autonomic neuroendocrine function $[4,14-16]$ and mental health $[4,14,17]$ in offspring. Treatment recommendations range from psychotherapy or anti-depressants for moderate cases to electroconvulsive therapy or a tricyclic combined with an anti-psychotic for depression with psychosis [18]. Prevailing medical opinion advocates that the consequences of leaving antenatal depression pharmacologically untreated is comparable to or greater than the risks associated with anti-depressant side effects and toxicity $[11,19,20]$. Yet, the efficacy of anti-depressants in pregnancy remains untested in large randomised controlled trials (RCTs), and, whilst expected to be comparable to those observed in non-pregnant populations [21], pregnancy-related pharmacokinetic changes may necessitate a need for increased dosage [20, 22]. Clinicians often reduce prescriptions in an attempt to limit foetal exposure, and resultant levels may therefore be subtherapeutic [22]. Recent evaluations of anti-depressant response rates in non-pregnant populations report modest improvements ranging from $14 \%$ [23] to $32 \%$ overall [24], and more than $50 \%$ of cases failing to achieve remission [25]. Treatment compliance is also an issue, with $45 \%$ partially [26] and $42 \%$ completely discontinuing medication within the first 3 months $[27,28]$, due in part to unwanted adverse effects [27, 29]. This is especially the case in intentionally conceiving or pregnant women, in whom cessation of medication is particularly common [9, 29], resulting in relapse rates of $68 \%$ compared to $26 \%$ in those who continue medication [30]. Combined pharmacologic treatments and psychotherapies, although considered to be more efficacious, also appear to be limited in regard to depression severity and chronicity [31].

Studies indicate that depressed pregnant women are reluctant to take anti-depressant medication [9, 32] and are significantly more likely to voice a preference for non-pharmacologic options [33, 34]. Preliminary research into acupuncture for the management of antenatal depression, although limited to three clinical studies, appears promising and reflective of similar findings in systematic reviews of acupuncture as a treatment for depression
[35-37]. In the first antenatal depression RCT, published in 2004, Manber and co-workers [38] compared 12 sessions of depression-specific, manualised acupuncture with 'sham' acupuncture and a massage control in 61 pregnant women with major depression. Significantly higher response rates were reported for depression-specific acupuncture (69\%) compared with massage (32\%) ( $p=0.031)$ and a non-significant intermediate response rate in comparison to sham (47\%). The depression-specific acupuncture group also demonstrated a significantly higher average rate of reduction in depression scores within the first month of treatment compared with the massage control $(p=0.047)$. In 2010, Manber et al. [39] conducted a larger RCT of 150 pregnant women and demonstrated significantly decreased symptom severity in the acupuncture group $(p<0.05)$ compared with combined control subjects or sham alone, as well as significantly greater response rates $(63.0 \%)$ compared with combined controls $(p<0.05)$ or sham alone $(p<0.05)$. In 2007, Bosco Guerreiro da Silva [40] similarly investigated emotional complaints in pregnancy by quasi-randomising 51 women to a preprogrammed acupuncture protocol with four optional points or a non-treatment control. Symptom severity reportedly reduced by up to $50 \%$ in 15 (60\%) of 25 subjects in the acupuncture group compared with 5 (26\%) of 19 in the control group $(p=0.013)$. In addition, significant reductions in the impact of distress in 3 of 5 life disturbance categories were also reported $(p<0.05)$. Whilst the findings of these three trials appear encouraging, the overall methodological quality is limited by small sample sizes [38, 40], quasi-randomisation and lack of an equivalent attention control [40], unclear randomisation generation and concealment $[9,38]$, unclear assessor blinding $[9,38,40]$, and incomplete baseline and outcome data $[9,38]$. Participant and practitioner blinding was performed in the two RCTs $[38,39]$, as was outcome assessor blinding in one $[9,39]$. In all three studies, emotional distress was clinically evaluated.

How acupuncture may reduce depressive symptomology remains uncertain; however, one mechanism by which it may exert an effect is via the oxytocinergic system. This system, regulated by both oxytocin (OT) hormone levels and oxytocin receptor (OTR) activity [41], is responsive to stressors of both physical and psychological origin [42]. The resultant anti-anxiolytic, anti-depressive and stress reducing effects $[41,43]$ appear to result from adjustments to the hypothalamic-pituitary axis, autonomic nervous system activity [44] and reward centres in the brain [43]. A multitude of physical [42], psychosocial, emotional and behavioural functions [44-48], including mental health and parental-infant bonding [49], have been attributed to this system, and, not surprisingly, disruptions within it are also implicated in a plethora of negative emotional and 
social phenotypic traits [50]. Studies of the relationship between mental health and the oxytocinergic system are suggestive of dysregulation [51], as lowered [52-60] and elevated OT and OTR levels [51,61-66], as well as dysregulated patterns of peripheral OT release [66], are seen in participants with depression in a variety of different observational and experimental conditions. The influence of acupuncture upon this system has also been assessed in 12 rodent studies and 1 human study, in which significant positive regulatory effects were reported, directly via radioimmunoassay and/or enzyme-immunoassay or quantitative real-time polymerase chain reaction (qRT-PCR) analysis [67-74], as well as indirectly via assessment of behaviour [75-79]. Further indirect evidence has been provided by 11 human studies examining acupuncture for the preparation, induction or enhancement of labour. Among these studies, significantly reduced requirements for syntocinin augmentation were reported in the acupuncture groups of nine studies [80-88], as was a trend toward less need in the acupuncture group of another [89]. In the remaining study, acupuncture was performed in addition to intravenous syntocinin, and labour effectiveness rates were also significantly improved [90]. Marginal non-significant elevations in syntocinin use were reported in two similar studies [91, 92]; however, methodological issues in both cases may have compromised the results.

As preliminary evidence is suggestive that acupuncture may be beneficial in reducing the severity of antenatal depression and may exert a regulatory effect upon the oxytocinergic system, additional research is warranted to determine whether acupuncture is a viable alternative therapeutic option. The aim of this study is to conduct an RCT to examine the hypotheses that acupuncture, compared with an attention comparator or usual care, reduces the severity and duration of antenatal depression, stress and anxiety; decreases adverse maternal and infant outcomes; improves maternal quality of life and infant bonding; and positively regulates OT and OTR expression.

\section{Methods/design}

\section{Overview}

A pragmatic, parallel-group RCT will be conducted to compare individually tailored, semi-standardised, depression-specific acupuncture with an equivalent attention progressive muscle relaxation (PMR) comparator and usual care. The morbidity of this population is sufficiently serious to maintain existing treatment and evaluate the interventions as adjunctive therapies [93]. The trial design incorporates individualised treatment flexibility [94], typical of a 'whole systems' approach $[95,96]$, within the framework of a semi-standardised protocol [97-100] and is thereby reflective of the recent emphasis on effectiveness studies of acupuncture interventions to maintain ecological validity [101] as well as generalisability and interpretability [98, 99]. The non-specific, placebo-like effects resulting from intervention participation [102, 103] will be estimated via the attention comparator, whereas antenatal depression progression or remission and compliance to standard therapy will be monitored via the non-treatment control [100].

Ethical approval for this study was granted in February 2015 by the Research and Ethics Office of the New South Wales Department of Health, South West Sydney Local Health District (SWSLHD-HREC/14/LPOOL/400) and the Western Sydney University Human Research Ethics Committee (WSU-HREC/H10993). The trial is registered with the Australian New Zealand Clinical Trials Registry (ACTRN12615000250538). The protocol (version 1.0) has been designed in accordance with the SPIRIT (Standard Protocol Items: Recommendations for Interventional Trials) guidelines for interventional trials $[104,105]$ (see Additional file 1) and will be conducted in accordance with the Declaration of Helsinki (1964) and the International Conference on Harmonization Good Clinical Practice (1996). Any changes that need to be made to the trial protocol will be communicated to all investigators, the ethics committees and the trial registry.

\section{Eligibility criteria}

Women will be eligible if they are at 24 weeks of gestation, $\geq 18$ years of age, have mood disorders and score $\geq 13$ on the Edinburgh Postnatal Depression Scale (EPDS) [106] (indicative of a high probability of current depression) $[106,107]$. Women will be excluded if they are experiencing a medically diagnosed major depressive episode $\geq 2$ years in duration and/or have psychotic or manic features rendering them incapable of consent, posttraumatic stress disorder with needle phobia, a current psychiatric assessment of suicidal risk, a condition necessitating bed rest, and/or other major obstetric risks. Participants must also agree not to receive acupuncture or PMR other than that provided within the study.

\section{Recruitment, setting and informed consent}

The study is being conducted at two hospital sites in South Western Sydney, Australia. Both sites provide antenatal outpatient services and are under the governance of the same health authority; however, birthing services are available only in the larger of the two. The region serviced includes suburbs considered to be of disadvantaged SES [108], high ethnic diversity and greater than state average indigenous population density $[108,109]$. Pregnant women will be introduced to the study via flyers included in antenatal information packs. Antenatal staff will additionally supply a study poster to all women identified with elevated EPDS scores during routine antenatal screening. Details of these women will be provided to the researcher, who, upon 
contact, will forward participant information sheets to all interested potential recruits. Once agreeing to join the study, all women will be further screened and, if eligible, randomised after signed informed consent forms containing separate provisions for the collection and use of biological specimens have been obtained in every case (Additional file 2).

\section{Randomisation and blinding}

Participants and practitioners are not blinded to the study; however, data entry and analysis will be blinded. The randomisation schedule was computer-generated to contain three groups of random numbers, enabling stratification for the three different models of antenatal care (obstetrician, standard and caseload midwifery) as well as to randomly contain 'blocks of three' within each group, acupuncture, PMR or usual antenatal hospital care (1:1:1). The schedule was generated by the school statistician (Paul Fahey) and concealed in opaque envelopes by an independent researcher from the National Institute of Complementary Medicine (NICM) (Anthony Good).

\section{Treatment and assessment schedules}

The study period will run for 8 consecutive weeks from gestation week 24 to the end of week 31 (Fig. 1). At baseline, age, gestational age, number of previous pregnancies and/or births, relationship status and/or quality, education, employment status and country of birth will be collected, along with depression-related clinical data, including medical diagnoses, entry EPDS score, age of onset and length of index episode, number and severity of past depressive episodes, length and severity of current episode, family history of depression and current medication and/or psychotherapy use. Collected data will be de-identified and securely stored at the NICM.

\section{Safety monitoring}

Owing to the morbidity of this population, women will undergo a weekly psychological assessment with the Kessler 6 (K6) instrument [110], either during the weekly session (intervention groups) or by telephone (usual care). If notable worsening or a 'cut-off' score is reached, immediate referral will be made to hospital antenatal mental health services. Any adverse events arising from the acupuncture intervention will be documented and reported to Western Sydney University and the South West Sydney Local Health District, and prevalence will be calculated. Such events are reportedly rare (occurring approximately 1.3 times every 1000 treatments) and generally of a mild $[111,112]$ to moderate nature [112]. However, if such

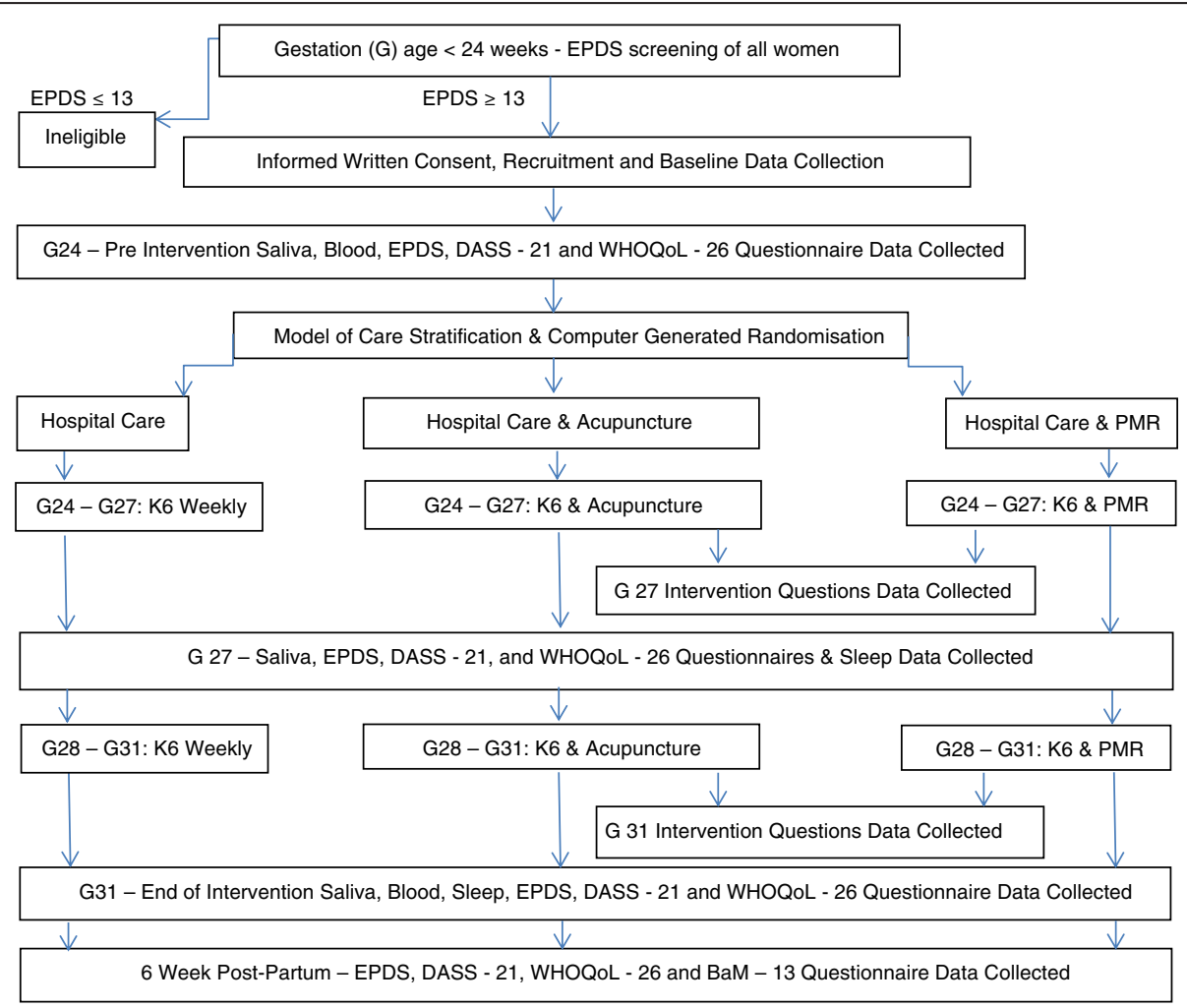

Fig. 1 Pragmatic randomised controlled trial treatment flowchart. EPDS Edinburgh Postnatal Depression Scale, G gestational week, DASS-21 21-item Depression Anxiety and Stress Scale, WHO-QoL-26 26-item World Health Organisation Quality of Life Scale, K6 Kessler 6 instrument, PMR progressive muscle relaxation, BaM-13 13-item Being a Mother Scale 
events do occur, participants will be reminded of their right to withdraw from the study at any time.

\section{Interventions}

In the first session, a full case history will be taken and a traditional Chinese medicine (TCM) and meridian therapy diagnosis will be made. This will also occur for the usual care group upon trial entry. The intervention groups will then receive weekly 1 -h treatments over the 8 -week period. At the end of each session, 5 minutes will be spent gaining feedback regarding the session. Treatments will be conducted in the antenatal clinics of either hospital or at the NICM.

The acupuncture protocol draws upon TCM theoretical foundations and treatment strategies as well as some generalisable traditional East Asian medicine approaches. The three-stage semi-standardised flexible process (Fig. 2) incorporates a 'root'- and 'branch'-style treatment $[113,114]$ as well as auricular acupuncture. The 'root' treatment (step 1) aims to provide a fundamental harmonisation via the extraordinary meridian system, while the 'branch' treatment (step 2) focuses on remaining disruptions in a more symptomatic way [114-116]. Use of the extraordinary meridian system as a root-style approach has been suggested to facilitate a longer-lasting, more penetrating effect $[114,116]$ by virtue of this system's ability to regulate the 'qi' of all of the yin-and-yang channels [117], access and distribute 'pre-

\begin{tabular}{|c|}
\hline Step 1 \\
\hline $\begin{array}{l}\text { 'Root' - Needle MP RHS, CP LHS of disharmonious } \\
\text { Extraordinary Meridian Pair }-10-15 \text { min. }\end{array}$ \\
\hline $\begin{array}{c}\text { Palpate GV Line \& HJJ } \quad \begin{array}{c}\vee \\
\text { Step } 2 a\end{array}\end{array}$ \\
\hline $\begin{array}{l}\text { Remove in the reverse order. Needle } 2 \text { most painful } \\
\text { GV line or HJJ points - retain for } 15 \text { min. }\end{array}$ \\
\hline $\begin{array}{lll}\begin{array}{l}\text { Whilst retained } \\
\text { GV } 16 \text { \& GV } 20\end{array} & \text { or } \\
& + \text { Step } 2 \mathrm{~b}:\end{array}$ \\
\hline $\begin{array}{l}\text { Add up to } 2-6 \text { points - based on presenting } \\
\text { symptoms - see table } 2 \text { - } 3 \text { for options }\end{array}$ \\
\hline After a total of $15-20 \mathrm{~min} \underset{\text { Step } 3}{\downarrow}$ remove needles \\
\hline $\begin{array}{l}\text { Add } 2 \text { press balls to auricular points for retention - } \\
\text { see table } 4 \text { for options }\end{array}$ \\
\hline $\begin{array}{l}\text { Fig. } 2 \text { Acupuncture treatment flowchart. CP coupled points, GV } \\
\text { governor vessel, HJJ Huato Jia Ji, LHS left-hand side, MP master points, } \\
\text { RHS right-hand side }\end{array}$ \\
\hline
\end{tabular}

heaven essence' throughout the entire body $[116,118]$ and affect a person at a constitutional level, due to its embryological roots $[116,118,119]$. Specific functions relevant to depression include influences to the marrow [116], brain, spinal chord, hypothalamic-pituitary-ovarian axis [120], circulatory, hepatic, biliary [121] and endocrine [118] systems. Pathology within this system is thought to manifest in the mind or 'shen' [118], and as such treatment is recommended for mental and/or emotional problems [118, 120] as well as cases of mixed pattern complexity involving multiple meridians [118]. In step 1, diagnosis of the most disharmonious extraordinary meridian pair will be made on the basis of the presence of relevant mood disturbance symptomology [116] in combination with disease indicating palpatory findings along involved channel trajectories [117-119]. If uncertainty remains regarding which of the 2 points of the meridian pair will be the master point (MP), each point will be tested with acupressure to see which one provides the greatest meridian improvement. After identification, the gender-appropriate MP and coupled point (CP) (Table 1) will be unilaterally needled with the meridian flow to ensure that the areas traversed by both vessels are influenced [118]. This method was recommended by Maciocia in 2006 [118] for problems of the head and internal organs, weakened body condition and anxiety. It is also suitable for pregnant women in side-lying position. Japanese-style practitioners typically apply polarity devices to the MP and $\mathrm{CP}$ to remedy detected pathologies in the extraordinary vessel system $[119,122]$. However, for the purposes of generalisability, polarity in this case will be achieved by side of sexdirected unilateral needling and reverse-order withdrawal [116]. Whilst needles are retained for 10-15 minutes, further diagnosis will be performed by palpation and questioning. As many of the symptoms of depression correspond to TCM 'yang deficiency' such as lethargy, reduced libido and lack of motivation [116], it has been theorised that disruption to the major yang channel, the extraordinary meridian governor vessel (GV) that traverses the middle of the back and head, is implicated in depression [123]. Treatment recommended by Wang and Zhang in 2010 [123] is the needling of the most painful or obstructed points along this channel or on the slightly adjacent Huato Jia Ji (HJJ) points, serving a dual main channel and extraordinary vessel function [118]. Step 2a will involve needling of the two points located in this way, in combination with either GV 20 (bai hui) [124] + GV 16 (feng fu) [124], the 'Sea of Marrow', indicated for mania, suicidal tendencies and calming the spirit; or 'Shi Shen Cong 4-4 Alert spirits', indicated for mania, depression, insomnia and calming of the spirit [117]. Selection in either case will be based upon palpation tenderness and/or symptom differentiation. Whilst these needles are retained, step $2 \mathrm{~b}$ will involve the needling of two to six additional tender points, if required, according to numerous theoretical possibilities (see Tables 2 and 3) 
Table 1 Master and coupled point pairings of the eight extra vessels

\begin{tabular}{lll}
\hline Extraordinary meridian & Master point (right) & Couple point (left) \\
\hline Ren Mai - Directing Vessel & Lung (LU) 7 (lie que) & Kidney (KD) 6 \\
Yin Qiao Mai -Yin Heel Vessel & Kidney (KD) 6 (zhao hai) & Lung (LU) 7 \\
Chong Mai - Penetrating Vessel & Spleen (SP) 4 (gong sun) & Pericardium (PC) 6 \\
Yin Wei Mai - Yin Linking Vessel & Pericardium (PC) 6 (nei guan) & Spleen (SP) 4 \\
Dai Mai - Girdle Vessel & Gallbladder (GB) 41 (zu lin qi) \\
Yang Wei Mai - Yang Linking Vessel & Triple burner (TB) 5 (wai guan) & Triple burner (TB) 5 \\
Du Mai - Governing Vessel & Small intestine (SI) 3 (hou xi) & Gallbladder (GB) 41 \\
Yang Qiao Mai - Yang Heel Vessel & Bladder (BL) 62 (shen mai) & Bladder (BL) 62 \\
\hline
\end{tabular}

The eight extra vessels are described by Maciocia [116].

${ }^{\text {a }}$ From Ellis et al. [124]

such as the ability to clear reflex areas, for a combined total time of $15-20$ minutes. A step $2 \mathrm{~b}$ example is the association between depression and inflammation [125] viewed as 'heat' in TCM; hence, if detected at a 'fire' point on a meridian trajectory, a remedying treatment involving the needling of 'water' and 'metal' points' [116] to extinguish the 'fire', may be selected. Step 3 will then comprise two stainless steel pellets (Helio Supply Co., San Jose, CA, USA) being placed on appropriate points in the ear (Table 4) to extend the treatment effect [122] for an additional 5 days. Lifestyle and dietary advice, contraindicated labour augmentation points [126] and painful needling techniques will be avoided [127]. Needles will be inserted into the most sensitive area within the specified point location or 'live' point [100] to a depth enabling retention (2-6 $\mathrm{mm}$ ), either perpendicularly (even technique) or obliquely with the

Table 2 Step 3: Additional relevant point possibilities

\begin{tabular}{|c|c|}
\hline Symptom and theoretical foundation & Points \\
\hline Severe Yang deficiency ${ }^{a}$ & $\begin{array}{l}\text { GV } 4 \text { (ming men) })^{b} \text { and GV } 14 \text { (da zhui) or GV } 4 \text { and TB } 4 \\
\text { (yang chi) }\end{array}$ \\
\hline $\begin{array}{l}\text { Anxiety }+ \text { pressure pain at PC } 8 \text { (lao gong) or SP } 2 \text { (da du) - pericardium } \\
\text { or spleen metal and water points }{ }^{c, d}\end{array}$ & $\begin{array}{l}\text { PC } 3 \text { (qu ze) and } 5 \text { (jian shu) or SP } 5 \text { (shang qiu) and } 9 \\
\text { (yin ling quan) }\end{array}$ \\
\hline Anxiety + pressure pain at CV 12 (zhong wan) - points of the heart shu area ${ }^{d}$ & T5/HJJ/BL 15 (xin shu)/BL 44 (shen tang)/BL 49 (yi she) \\
\hline Anxiety + pressure pain at CV 17 (dan zhong) ${ }^{d}$ & GB 13 (ben shen) \\
\hline Depression/mental disturbance - 'blood stagnation in the head'c & First - SP 9 (yu ling quan) second - PC 8 or PC 6 or PC $3+5$ \\
\hline Depression due to adrenal exhaustion ${ }^{c, d}$ & KD 6 and lateral to LU 5 (chi ze) or KD 6 and KD 27 (shu fu) \\
\hline $\begin{array}{l}\text { Depression and sphenoid bone disturbance - pressure pain at GB } 4 \text { (han yan)/5 } \\
\text { (xuan lu)/6 (xuan li) })^{\mathrm{d}}\end{array}$ & Needle most tender \\
\hline Depression and sphenoid bone disturbance - pressure pain TB 17 (yi feng) and TMJ & KD 9 (zhu bin) and 27 and above TB 9 (si du) side of pain \\
\hline Depression and pituitary disturbance ${ }^{c}$ & $\begin{array}{l}\text { SI 3, SI } 13 \text { (qu yuan), BL } 2 \text { (zan zhu) and } 1 \text { cun above BL } 10 \\
\text { (tian zhu) }\end{array}$ \\
\hline Melancholic depression $^{d}$ - if positive for pressure pain/pulsation at CV 9 (shui fen) ${ }^{d}$ & ST 24 (hua rou men) RHS, LU 9 (tai yuan) \\
\hline Depression - LR 2 (xing jian) pressure pain - water and metal points ${ }^{c}$ & LR 4 (zhong feng) and 8 (qu quan) \\
\hline Depression - pressure pain LR organ region and LR 14 (qi men) ${ }^{c}$ & LHS - lateral to LU 5 (chi ze), LR 4 and LR 14 RHS \\
\hline 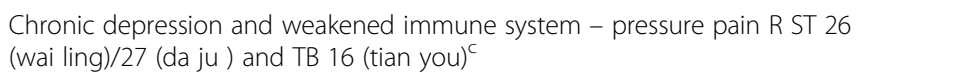 & Tender point around LI 10 (shou san li)/11 (qu chi) \\
\hline Subclinical underactive thyroid gland ${ }^{c}$ & $\begin{array}{l}\text { Eustachian, TB 4, KD 9/10 (yin gu), BL } 43 \text { (gao huang shu), } \\
\text { HJJ C6/7 }\end{array}$ \\
\hline Inflammation - TCM meridian heat signs - metal and water points to extinguish ${ }^{e}$ & Meridian-dependent \\
\hline Mental health relevant points - selected by point function and palpation tenderness & See Table 3 for options \\
\hline
\end{tabular}

BL bladder meridian, $C V$ conception vessel, GB gallbladder meridian, GV governor vessel, $H J J$ Huato Jia Ji, $K D$ kidney meridian, $L H S$ left-hand side, $L U$ lung meridian, $L /$ large intestine meridian, $L R$ liver meridian, $P C$ pericardium meridian, SP spleen meridian, $S T$ stomach meridian, $R H S$ right-hand side, $S /$ small intestine meridian $T B$ triple burner meridian, TCM traditional Chinese medicine

${ }^{a}$ Maciocia [116]

${ }^{\mathrm{b}}$ Ellis et al. [124]

'Matsumoto and Euler [134]

${ }^{\mathrm{d}}$ Matsumoto and Euler [135]

${ }^{\mathrm{e}}$ Kendall-Tackett [125] 
Table 3 Possible points and point combinations useful for the treatment of antenatal depression

\begin{tabular}{|c|c|}
\hline Points & Indications/Symptom alleviation \\
\hline ST 40 (feng long) ${ }^{a}$ & Spleen deficiency, damp and phlegm misting - heaviness, confusion, metal disturbance \\
\hline ST 23 (tai yi) & Transforms phlegm and calms the spirit - mania, depression, agitation \\
\hline ST 24 (hua rou men) & Transforms phlegm and calms the spirit - mania, depression \\
\hline LR 3 (tai chong) & LR Qi stagnation, irritability, feeling of oppression \\
\hline BL 42(po hu) & Breathing difficulties, grief, worry, sadness \\
\hline BL 43 & Increases spleen yang and lung function, calms the spirit, resolves phlegm \\
\hline BL 44 & Calming and mental clarity \\
\hline BL 47 (hun men) & Enables clear and positive life planning and decision making \\
\hline BL 47 and BL 52(zhi shi) & Together adds stability to plans and decisions, also for LR Qi stasis attack on lungs \\
\hline BL 49 & Obsessive thinking, improved memory and concentration \\
\hline BL 52 & Willpower, determination, initiation \\
\hline BL 52 and $B L 42$ & Willpower and emotional release \\
\hline BL 52 and BL 44 & Willpower, calming, anxiety, depression, mental restlessness and insomnia \\
\hline BL 52 and BL 47 & Willpower and life direction, chronic depression with mental exhaustion, apathy and despondency \\
\hline BL 52 and BL 49 & Willpower, obsessive thoughts, worry and confusion \\
\hline BL 10 (tian zhu) & Calms the spirit \\
\hline BL 17 (ge shu) & Mania, depression \\
\hline GV 18 (qiang jian) & Liver blood deficiency, calming, mental restlessness, agitation, confusion, obsessive thinking \\
\hline GV 19(hou ding) & Willpower, calming, anxiety, mental restlessness, kidney yin deficiency heat \\
\hline GV 19 and CV 15 (jiu wei) & Calming, insomnia, mental restlessness \\
\hline GV 20 (bai hui) & Lifts mood, aids memory and concentration \\
\hline GV 21 (qian ding) & Anxiety, insomnia, depression \\
\hline GV 24 (shen ting) & Clears the mind \\
\hline GV 24 and GB 13 & Calming, anxiety, mental restlessness due to LR causes \\
\hline CV 14 (ju que) & Transforms phlegm and calms the spirit \\
\hline CV 15 & Calming, chest oppression \\
\hline GB 9 (tian chong) & Calms the spirit and pacifies fright \\
\hline GB 12(wang gu) & Mania, agitation of the heart and insomnia \\
\hline GB 13 & Calming, mental clarity, severe anxiety and mental restlessness resulting from LR disharmony \\
\hline GB 13 and GV 24 & Same as for GB 13 with enhanced calming effect \\
\hline GB 13 and HT 7 (shen men) & Calming, severe anxiety due to heart disharmony \\
\hline GB 15 (tou lin qi) & Calms the spirit, reduces emotional fluctuations and obsessive thinking \\
\hline GB 17 (zheng ying) & Calms the spirit, aids memory and concentration \\
\hline GB 18 (cheng ling) & Stops obsessive thoughts, strengthens the function of the lungs and clears the nose \\
\hline GB 40 (qiu xu) & Willpower, difficulty making decisions \\
\hline HT 7 & Calms the spirit, heart blood and yin deficiency \\
\hline HT 6 (tong li) & Calms the spirit, repletion patterns with vacuity heat \\
\hline HT 8 (shao fu) & Calms the spirit - agitation, fright palpitations, depleted sadness and worry \\
\hline HT 9 (shao chong) & Calms the spirit - mania, depression, severe mental restlessness, anxiety, insomnia \\
\hline HT 5 (tong li) & Calms the spirit - depressive disorder \\
\hline PC 4 (xi men) & Calms the spirit - agitation, insomnia, melancholy, spirit qi deficiency \\
\hline HT 7 and PC 6 & Calms the spirit - shen disturbance, anxiety, mental restlessness \\
\hline KD 7 ( fu liu) and HT 6 (yin xi) & Calms the spirit - heart and kidney not communicating, agitation, insomnia, anxiety \\
\hline PC 5 & Settles and calms the spirit - mania and agitation \\
\hline
\end{tabular}


Table 3 Possible points and point combinations useful for the treatment of antenatal depression (Continued)

\begin{tabular}{ll}
\hline PC 7 (da ling) & Calms the spirit - depressive disorder \\
PC 6 & Calms the spirit, lifts mood - qi stagnation emotional problems, anger, resentment and frustration \\
PC 6 and SP 4 & Opens yin wei mai, nourishes blood, relaxes the chest, calms the spirit \\
PC 6 and LR 3 & Resolves qi stasis from repressed anger \\
PC 6 and GV 20 & Lifts the mood, relieves depression \\
PC 6 and GV 26 (shu gou) & Lifts the mood, opens heart orifices, relieves depression \\
SI 7 (zhi zheng) & Calms the spirit - mania, depression, anxiety, sadness, fear and fright \\
KD 9 (zhu bin) & Clears the heart and transforms phlegm - mental restlessness, mania, depressive disorders \\
SI 7 and HT 3 (shao hai) & Chronic anxiety, depression, fear or emotional distress \\
LI 5 (yang xi) & Calms the spirit - mania, depression
\end{tabular}

BL bladder meridian, $C V$ conception vessel, GB gallbladder meridian, GV governor vessel, HJJ Huato Jia Ji, KD kidney meridian, $L H S$ left-hand side, $L U$ lung meridian, L/ large intestine meridian, $L R$ liver meridian, $P C$ pericardium meridian, $S P$ spleen meridian, $S T$ stomach meridian, $R H S$ right-hand side, $S /$ small intestine meridian Information is from MacPherson and Schroer [98]; Schnyer and Allen [99]; Deadman et al. [117]; Matsumoto and Euler [136]; and Rogers and Rogers [147] ${ }^{\mathrm{a}}$ Ellis et al. [124]

meridian flow (tonification) and taped in place to allow for adjustment of position during the session. AcuGlide (Helio Supply Co.) single-use stainless steel needles $0.16 \mathrm{~mm} \times$ $30 \mathrm{~mm}$ will be used predominantly, with $0.14-\mathrm{mm}$ or 0.12-mm needles selected for tenderer locations.
In our examination of recent reviews of acupuncture as a treatment for depression [35, 36, 128-130], we identified three main treatment approaches previously used: (1) fixed points for mood disturbance alleviation, (2) fixed points of this function in combination with additional points selected

Table 4 Auricular point possibilities

\begin{tabular}{|c|c|}
\hline Name & Function \\
\hline Point Zero & Homeostasis, will power \\
\hline Shen men & Pain, tension, anxiety and depression \\
\hline Sympathetic tone & Sympathetic nervous system balance \\
\hline Cheerfulness & Relieves depression \\
\hline Excitement & Relieves hypersomnia and depression \\
\hline Master cerebral point & Anxiety, worry, obsessive compulsive disorders, psychosomatic disorders and chronic pain \\
\hline Master oscillation point & Balances left and right cerebral hemispheres \\
\hline Sleep disorders 1 & Relieves insomnia, nervousness \\
\hline Sleep disorders 2 & Relieves insomnia, sleep difficulties, nervous dreams \\
\hline Depression & Relieves depression \\
\hline Endocrine & Hormone imbalance \\
\hline Nervousness & Relieves nervousness \\
\hline Adrenal & Adrenal fatigue/disturbance \\
\hline Thyroid 1-4 & Thyroid function disturbance \\
\hline Marvellous/wonderful & Lifts mood \\
\hline Aggression & Alleviates aggression/irritability \\
\hline Mania & Relieves manic symptomology \\
\hline Insomnia & For sleep disturbance \\
\hline Vitality & For lethargy and despondency \\
\hline Stress control & Relieves stress \\
\hline Tranquilizer & Calms the spirit \\
\hline Guilt & Alleviates feeling of guilt \\
\hline Overwhelmed & Stress, emotional paralysis, despondency \\
\hline Burdened & Emotional paralysis, despondency, overwhelm \\
\hline
\end{tabular}

Adapted from several different Chinese medicine-based auricular maps obtained from the internet: https://www.google.com.au/search?q=chinese+auricular+ear + acupuncture+chart\&biw =1140\&bih=610\&tbm=isch\&tbo=u\&source=univ\&sa=X\&ved=0ahUKEwjO6ofuuebKAhXEUZQKHR-UAAkQsAQIGg. 
according to TCM pattern differentiation and (3) flexible point selection based entirely upon TCM pattern discrimination. Variations included diagnosis of disrupted extraordinary vessels Chong and Ren in one study [131], an abdominal points focus in another [132] and scalp acupuncture in a third [133]. Many studies included auricular acupuncture as well as multiple points along the extraordinary GV meridian. Two research groups developed flexible manualised protocols based on pattern differentiation $[98,99]$, one of which also provided modifications for pregnancy [99]. Both have been drawn upon for therapeutic possibilities presented in Tables 2 and 3, in combination with those suggested by Matsumoto and Euler in 2002 [134] and 2008 [135], such as for the alleviation of commonly observed LR Qi stagnation [98]. It is theorised that the approach of extraordinary meridian treatment in combination with mental disturbance-oriented pattern differentiation and symptom alleviation may provide additional therapeutic outcomes. In 2009, Finston [136] used a similar strategy in patients with severe mental disorders and reported significant reduction or alleviation of psychotic symptoms [136].

The PMR comparator has been adapted from previous research [137] to achieve overall body relaxation in all sessions with an additional weekly focus as follows: introduction (week 1); lower legs and knees (week 2); upper legs and buttocks (week 3); lower back and pelvic floor (week 4); upper back and chest (week 5); arms and shoulders (week 6); head, face and neck (week 7); and integration (week 8). Participants, whilst lying in a comfortable position, will be guided through the PMR in a one-to-one format. A participant who is unable to attend will be offered either a recording- or telephone-based session for home administration.

All groups will continue standard antenatal care, which may include medication and or counselling as well as antenatal classes. In compensation for not receiving treatment, the usual care group will be offered four acupuncture sessions after collection of final data at 6 weeks post-natally.

The principal investigator of this trial (SMO) has 14 years of full-time clinical experience and will conduct all acupuncture sessions, unless unable, in which case a backup acupuncturist with 14 years of part-time clinical experience will be employed. Both practitioners have bachelor's degrees in acupuncture and are registered with the Chinese Medicine Board of Australia and the Australian Acupuncture and Chinese Medicine Association. The principal investigator will also conduct all PMR sessions, unless unable, in which case a backup associate researcher will be employed.

\section{Outcome measures}

Data and samples will be collected at various time points, including baseline, mid-intervention (week 4), end of intervention (week 8), birthing and hospital discharge (medical records) and 6 weeks post-natally. All questionnaires will be self-administered and collected by the principal investigator. The primary outcome endpoint, reduction in depression severity, will be assessed at baseline, at 4 and 8 weeks from trial entry and at 6 weeks post-natally via the EPDS, an extensively validated, clinically sensitive [138], 10item self-report questionnaire. Additional secondary outcome endpoints will also be examined as follows :

1. At the same time points as the EPDS, reduction in stress and anxiety will be monitored with the 21item Depression Anxiety and Stress Scale (DASS-21) [139] and improvement to quality of life will be evaluated using the 26-item World Health Organisation Quality of Life Scale (WHO-QoL-26,) [140]. The DASS-21 is a short form of the clinically validated [141] and cross-culturally reliable [142] self-report measure of emotional states of stress and anxiety. The WHO-QoL-26 [140] is also an abbreviated form of this discriminant, content valid, internally consistent and reliable self-report measure for overall quality of life.

2. Adjustment to parenting and maternal-infant bonding will be evaluated at 6 weeks post-natally via the 13-item Being a Mother Scale (BaM-13) [143]. The BaM-13 is a clinically discriminating, reliable and valid self-report tool specifically designed to enable early assessment of women's experiences of motherhood.

3. Maternal-infant outcomes such as gestational diabetes, mode of delivery, method of pain relief, labour augmentation, post-partum haemorrhage, breastfeeding level and duration, gestational age at delivery, birth weight, 1- and 5-minute Apgar scores, neonatal intensive care unit admission and need and reason for resuscitation and or intensive care will be assessed at delivery, discharge and 6 weeks post-natally.

4. Salivary OT levels will be determined using saliva specimens collected by the principal investigator at baseline and at 4 and 8 weeks from trial entry. Leucocyte OTR messenger RNA (mRNA) expression will be assessed using blood collected by phlebotomists at local pathology centres at baseline and 8 weeks from trial entry.

Every effort will be made to minimise missing data by ensuring weekly contact with participants during the intervention period as well as robust follow-up at later data collection points. Missing data for the primary endpoint of depression will be estimated using multiple imputation data derived from the $\mathrm{K} 6$ instrument. All missing data will be reported with reasons given and patterns of occurrence explored. 


\section{Sample analysis}

The principal investigator will process samples as follows. $4 \mathrm{ml}$ of saliva will be obtained via passive drool into sterile CELLSTAR polypropylene test tubes $(15 \mathrm{ml}$, catalogue number 188271; Greiner Bio-One, Frickenhausen, Germany), transported on ice and frozen and stored at $-20{ }^{\circ} \mathrm{C}$. Thawed samples will later be batch-processed and concentrated using equilibrated Sep-Pak C18 200mg resin cartridges (catalogue number WAT 054945; Waters Corporation, Milford, MA, USA) before refreezing at $-20{ }^{\circ} \mathrm{C}$ in 5 - $\mathrm{ml}$ sterile Eppendorf tubes (catalogue number 0030119401, Eppendorf, Hauppauge, NY, USA). Triplicate OT concentrations will be batch-calculated using an OT enzyme-linked immunosorbent assay (ELISA) kit (catalogue number ADI-901-153A-0001; Enzo Life Sciences, Farmingdale, NY, USA) and an ELISA plate reader. Blood $(2.5 \mathrm{ml})$ collected into PAXgene blood tubes (catalogue number 762165; BD Diagnostics, Hunt Valley, MD, USA) will be stored at $-20{ }^{\circ} \mathrm{C}$ no sooner than $2 \mathrm{~h}$ after collection. Batch extraction of mRNA will later be performed using PAXgene blood RNA kits (catalogue number 762174; BD Diagnostics) and stored at $-20{ }^{\circ} \mathrm{C}$ before cDNA libraries are made using iScript Advanced cDNA Synthesis kits (170-8843 Bio-Rad Laboratories, Hercules, CA, USA) and mRNA expression is determined by qRT-PCR using human OTR PCR primers (catalogue number VHPS-6555; Applied Biosystems, Foster City, CA, USA).

\section{Sample size}

Mean antenatal EPDS scores extracted from a recent Australian study [111], as well as estimated postintervention between-groups differences derived from a meta-analysis of two antenatal depression acupuncture studies [9], were used for a power calculation for this study. Using a power of $80 \%$ and two-sided testing at a $5 \%$ significance level, detecting a significant difference in end of intervention mean \pm standard deviation (SD) EPDS scores of $8.9 \pm 5$ for the acupuncture group plus usual hospital care versus $13 \pm 6.5$ for usual hospital care will require a total recruitment goal of 75 participants. As high attrition rates have been reported for this population [144], an additional recruitment of $30 \%$ has been added, resulting in a total goal of 96 , or 32 participants per group.

\section{Statistical analysis}

Descriptive statistics will be used to describe the characteristics of the study population. An intention-to-treat analysis will be undertaken [145], with between-groups differences explored using analysis of variance for the primary and secondary endpoints of depression, stress, anxiety, quality of life and OT/OTR. Effect sizes will be reported with $95 \%$ confidence intervals, and results will be considered significant if $p$ values are less than 0.05 .

\section{Discussion}

In consideration of the sufficiently serious consequences of antenatal depression in combination with therapeutic deficiencies, a thorough evaluation of any promising preventative and or therapeutic techniques that may be effective in reducing antenatal distress is required. As to date no studies have been conducted to investigate an acupuncture protocol of this type in depressed pregnant women or to evaluate the effects of acupuncture on the oxytocinergic system in this regard, it is the aim of this RCT to collect such data as well as to assess the usefulness of this acupuncture treatment for the alleviation of antenatal depression. Limitations of this study include the current lack of research evidence regarding the effectiveness of the proposed acupuncture treatment strategy, the use of self-report measures for the determination of treatment effect, a 'practice effect' that may occur due to repeated use of self-report measures and the unquantifiable possible effects of PMR that are in addition to non-specific placebo effects resulting from intervention procedures and interactions.

\section{Trial status}

Recruitment is ongoing.

\section{Additional files}

Additional file 1: SPIRIT 2013 Checklist. (DOC $124 \mathrm{~kb}$ )

Additional file 2: Consent form. (PDF $204 \mathrm{~kb}$ )

\section{Abbreviations}

BaM-13: 13-item Being a Mother Scale; BL: bladder meridian; CP: coupled points; CV: conception vessel; DASS-21: 21-item Depression Anxiety and Stress Scale; ELISA: enzyme-linked immunosorbent assay; EPDS: Edinburgh Postnatal Depression Scale; GB: gallbladder meridian; GV: governor vessel; HJJ: Huato Jia Ji; HT: heart meridian; K6: Kessler 6; KD: kidney meridian; LHS: left-hand side; LU: lung meridian; LI: large intestine meridian; LR: liver meridian; MP: master point; mRNA: messenger RNA; NICM: National Institute of Complementary Medicine; OT: oxytocin; OTR: oxytocin receptor; PC: pericardium meridian; PMR: progressive muscle relaxation; qRTPCR: quantitative real-time polymerase chain reaction; SD: standard deviation; SP: spleen meridian; ST: stomach meridian; RCT: randomised controlled trial; RHS: right-hand side; SES: socioeconomic status; SI: small intestine meridian; TB: triple burner meridian; TCM: traditional Chinese medicine; TMJ: temporomandibular joint; WHO-QoL-26: 26-item World Health Organisation Quality of Life Scale.

\section{Competing interests}

The authors declare that they have no competing interests.

\section{Authors' contributions}

SMO, CAS, HGD, PJH and JML designed the RCT. SMO is responsible for running all aspects of the clinical trial including screening; recruitment; intervention administration; sample collection, processing and analysis; data analysis; reporting, (in accordance with STRICTA guidelines for clinical trials of acupuncture interventions) [146] and communication of findings to participants. Data will be entered, including $20 \%$ double data entry, by an independent associate researcher from the NICM and analysed in consultation with the school statistician 
(Paul Fahey). SMO took the lead with preparing the manuscript, with CAS, HGD, $\mathrm{PJH}$ and $\mathrm{JML}$, commenting on drafts and giving final approval.

\section{Acknowledgements}

The authors acknowledge Dr Paul Fahey for preparation of the randomisation schedule and sample size calculation; Dr Anthony Good for concealment of the randomisation schedule; acupuncturists Dr Debra Betts and Paul Movsessian for advice regarding the acupuncture treatment protocol; Sharon Ellis, hospital antenatal service manager, for practical assistance in relation to trial implementation; and Dr Christine Chiu for assistance with laboratory-related matters. Funding for this research has been received in the format of an Australian post-graduate award scholarship, of which SMO is a recipient, and 'research training funds' provided by Western Sydney University as a standard resource to all higher degree by research candidates.

\section{Author details}

${ }^{1}$ PhD Candidate, National Institute of Complementary Medicine, Western Sydney University, Building 5, Campbelltown Campus, Locked Bag 1797, Penrith, NSW 2751, Australia. ${ }^{2}$ Professor of Complementary Medicine, National Institute of Complementary Medicine, Western Sydney University, Building 5, Campbelltown Campus, Locked Bag 1797, Penrith, NSW 2751, Australia. ${ }^{3}$ Professor of Midwifery, Western Sydney University, Building EB, Parramatta Campus, Locked Bag 1797, Penrith, NSW 2751, Australia. ${ }^{4}$ Chair of Mental Health, Western Sydney University, Building 30, Campbelltown Campus, Locked Bag 1797, Penrith, NSW 2751, Australia. ${ }^{5}$ Associate Professor, Molecular Biology and Genetics, Western Sydney University, Building 30, Campbelltown Campus, Locked Bag 1797, Penrith, NSW 2751, Australia.

Received: 5 June 2015 Accepted: 28 January 2016

Published online: 17 February 2016

\section{References}

1. Choate LH, Gintner GG. Prenatal depression: best practice guidelines for diagnosis and treatment. J Couns Dev. 2011;89(3):373-81.

2. Milgrom J, Gemmill AW, Bilszta JL, Hayes B, Barnett B, Brooks J, et al. Antenatal risk factors for postnatal depression: a large prospective study J Affect Disord. 2008;108(1-2):147-57.

3. Bennett HA, Einarson A, Taddio A, Koren G, Einarson TR. Prevalence of depression during pregnancy: systematic review. Obstet Gynecol. 2004; 103(4):698-709.

4. Field T, Diego M, Hernandez-Reif M. Prenatal depression effects on the fetus and newborn: a review. Infant Behav Dev. 2006;29(3):445-55.

5. Lancaster C, Gold K, Flynn H, Yoo H, Marcus S, Davis M. Risk factors for depressive symptoms during pregnancy: a systematic review. Am J Obstet Gynecol. 2010;202(1):5-14.

6. Edwards B, Galletly C, Semmler-Booth T, Dekker G. Antenatal psychosocial risk factors and depression among women living in socioeconomically disadvantaged suburbs in Adelaide, South Australia. Aust N Z J Psychiatry. 2008:42(1):45-50.

7. Sugiura-Ogasawara M, Furukawa TA, Nakano Y, Hori S, Aoki K, Kitamura T. Depression as a potential causal factor in subsequent miscarriage in recurrent spontaneous aborters. Hum Reprod. 2002;17(10):2580-4.

8. Nakano Y, Oshima M, Sugiura Ogasawara M, Aoki K, Kitamura T, Furukawa T. Psychosocial predictors of successful delivery after unexplained recurrent spontaneous abortions: a cohort study. Acta Psychiatr Scand. 2004; 109(6):440-6.

9. Dennis $\mathrm{CL}$, Dowswell T. Interventions (other than pharmacological, psychosocial or psychological) for treating antenatal depression. Cochrane Database Syst Rev. 2013;7:CD006795.

10. Grote NK, Bridge JA, Gavin AR, Melville JL, lyengar S, Katon WJ. A metaanalysis of depression during pregnancy and the risk of preterm birth, low birth weight, and intrauterine growth restriction. Arch Gen Psychiatry. 2010; 67(10):1012-24.

11. Hübner-Liebermann B, Hausner H, Wittmann M. Recognizing and treating peripartum depression. Dtsch Arztebl Int. 2012;109(24):419-24.

12. Leigh B, Milgrom J. Risk factors for antenatal depression, postnatal depression and parenting stress. BMC Psychiatry. 2008:8:24

13. Grote NK, Spieker SJ, Lohr MJ, Geibel SL, Swartz HA, Frank E, et al. Impact of childhood trauma on the outcomes of a perinatal depression trial. Depress Anxiety. 2012;29(7):563-73.
14. Diego MA, Field T, Hernandez-Reif M, Cullen C, Schanberg S, Kuhn C. Prepartum, postpartum, and chronic depression effects on newborns. Psychiatry. 2004;67(1):63-80.

15. Deave T, Heron J, Evans J, Emond A. The impact of maternal depression in pregnancy on early child development. BJOG. 2008;115(8):1043-51.

16. Ban L, Gibson JE, West J, Tata LJ. Association between perinatal depression in mothers and the risk of childhood infections in offspring: a population-based cohort study. BMC Public Health. 2010;10:799.

17. Pawlby S, Hay DF, Sharp D, Waters CS, O'Keane V. Antenatal depression predicts depression in adolescent offspring: prospective longitudinal community-based study. J Affect Disord. 2009;113(3):236-43.

18. Royal Australian and New Zealand College of Psychiatrists Clinical Practice Guidelines Team for Depression. Australian and New Zealand clinical practice guidelines for the treatment of depression. Aust N Z J Psychiatry. 2004:38(6):389-407.

19. Lewis AJ, Galbally M, Opie G, Buist A. Neonatal growth outcomes at birth and one month postpartum following in utero exposure to antidepressant medication. Aust N Z J Psychiatry. 2010;44(5):482-7.

20. Weisskopf E, Fischer CJ, Bickle Graz M, Morisod Harari M, Tolsa JF, Claris O, et al. Risk-benefit balance assessment of SSRI antidepressant use during pregnancy and lactation based on best available evidence. Expert Opin Drug Saf. 2015;14(3):413-27.

21. Yonkers KA, Wisner KL, Stewart DE, Oberlander TF, Dell DL, Stotland N, et al. The management of depression during pregnancy: a report from the American Psychiatric Association and the American College of Obstetricians and Gynecologists. Gen Hosp Psychiatry. 2009;31(5):403-13.

22. Sockol LE, Epperson CN, Barber JP. A meta-analysis of treatments for perinatal depression. Clin Psychol Rev. 2011:31(5):839-49.

23. Moncrieff J, Kirsch I. Efficacy of antidepressants in adults. BMJ. 2005; 331(7509):155-7.

24. Turner EH, Matthews AM, Linardatos E, Tell RA, Rosenthal R. Selective publication of antidepressant trials and its influence on apparent efficacy. N Engl J Med. 2008;358(3):252-60

25. Gartlehner G, Gaynes BN, Hansen RA, Thieda P, DeVeaugh-Geiss A, Krebs EE et al. Comparative benefits and harms of second-generation antidepressants: background paper for the American College of Physicians. Ann Intern Med. 2008;149(10):734-50.

26. Bulloch AG, Patten SB. Non-adherence with psychotropic medications in the general population. Soc Psychiatry Psychiatr Epidemiol. 2010;45(1):47-56.

27. Rivero-Santana A, Perestelo-Perez L, Pérez-Ramos J, Serrano-Aguilar P, De las Cuevas C. Sociodemographic and clinical predictors of compliance with antidepressants for depressive disorders: systematic review of observational studies. Patient Prefer Adherence. 2013;7:151-69.

28. American Psychiatric Association. Practice guideline for the treatment of patients with major depressive disorder. 2nd ed. Washington, DC: American Psychiatric Press; 2000

29. Manber R, Allen JJ, Morris ME. Alternative treatments for depression: empirical support and relevance to women. J Clin Psychiatry. 2002;63(7):628-40.

30. Cohen LS, Altshuler LL, Harlow BL, Nonacs R, Newport DJ, Viguera AC, et al. Relapse of major depression during pregnancy in women who maintain or discontinue antidepressant treatment. JAMA. 2006:295(5):499-507.

31. de Maat SM, Dekker J, Schoevers RA, de Jonghe F. Relative efficacy of psychotherapy and combined therapy in the treatment of depression: a meta-analysis. Eur Psychiatry. 2007;22(1):1-8.

32. Battle $C L$, Uebelacker LA, Magee SR. Patient-centered care for antenatal depression. Am J Obstet Gynecol. 2012;207(5):e10-1.

33. Dennis CL, Ross LE, Grigoriadis S. Psychosocial and psychological interventions for treating antenatal depression. Cochrane Database Syst Rev. 2007;3:CD006309.

34. Battle CL, Salisbury AL, Schofield CA, Ortiz-Hernandez S. Perinatal antidepressant use: understanding women's preferences and concerns. J Psychiatr Pract. 2013;19(6):443-53.

35. Stub T, Alræk T, Liu J. Acupuncture treatment for depression a systematic review and meta-analysis. Eur J Integr Med. 2011;3(4):e259-70.

36. Wu J, Yeung AS, Schnyer $R$, Wang $Y$, Mischoulon D. Acupuncture for depression: a review of clinical applications. Can J Psychiatry. 2012;57(7):397-405.

37. Wang H, Qi H, Wang BS, Cui YY, Zhu L, Rong ZX, et al. Is acupuncture beneficial in depression: a meta-analysis of 8 randomized controlled trials? Affect Disord. 2008:111(2-3):125-34

38. Manber R, Schnyer RN, Allen JJ, Rush AJ, Blasey CM. Acupuncture: a promising treatment for depression during pregnancy. J Affect Disord. 2004; 83(1):89-95. 
39. Manber R, Schnyer RN, Lyell D, Chambers AS, Caughey AB, Druzin M, et al. Acupuncture for depression during pregnancy: a randomized controlled trial. Obstet Gynecol. 2010;115(3):511-20.

40. Bosco Guerreiro da Silva J. Acupuncture for mild to moderate emotional complaints in pregnancy - a prospective, quasi-randomised, controlled study. Acupunct Med. 2007;25(3):65-71.

41. Gimpl G, Fahrenholz F. The oxytocin receptor system: structure, function, and regulation. Physiol Rev. 2001;81(2):629-83.

42. Heinrichs M, von Dawans B, Domes G. Oxytocin, vasopressin, and human social behavior. Front Neuroendocrinol. 2009;30(4):548-57.

43. Slattery DA, Neumann ID. Oxytocin and major depressive disorder: experimental and clinical evidence for links to aetiology and possible treatment. Pharmaceuticals (Basel). 2010;3(3):702-24.

44. Norman GJ, Hawkley L, Luhmann M, Ball AB, Cole SW, Berntson GG, et al. Variation in the oxytocin receptor gene influences neurocardiac reactivity to social stress and HPA function: a population based study. Horm Behav. 2012;61(1):134-9.

45. Lim MM, Young LJ. Neuropeptidergic regulation of affiliative behavior and social bonding in animals. Horm Behav. 2006;50(4):506-17. A published erratum appears in Horm Behav. 2007:51(2):292-3.

46. Ring RH, Schechter LE, Leonard SK, Dwyer JM, Platt BJ, Graf R, et al. Receptor and behavioral pharmacology of WAY-267464, a non-peptide oxytocin receptor agonist. Neuropharmacology. 2010;58(1):69-77.

47. Insel TR. The challenge of translation in social neuroscience: a review of oxytocin, vasopressin, and affiliative behavior. Neuron. 2010;65(6):768-79.

48. Chaviaras S, Mak P, Ralph D, Krishnan L, Broadbear JH. Assessing the antidepressant-like effects of carbetocin, an oxytocin agonist, using a modification of the forced swimming test. Psychopharmacology (Berl). 2010; 210(1):35-43.

49. Carter CS, Boone EM, Pournajafi-Nazarloo H, Bales KL. Consequences of early experiences and exposure to oxytocin and vasopressin are sexually dimorphic. Dev Neurosci. 2009;31(4):332-41.

50. Kumsta R, Hummel E, Chen FS, Heinrichs M. Epigenetic regulation of the oxytocin receptor gene: implications for behavioral neuroscience. Front Neurosci. 2013;7:83.

51. Parker KJ, Kenna HA, Zeitzer JM, Keller J, Blasey CM, Amico JA, et al. Preliminary evidence that plasma oxytocin levels are elevated in major depression. Psychiatry Res. 2010;178(2):359-62.

52. Garcia FD, Coquerel Q, Kiive E, Déchelotte P, Harro J, Fetissov SO. Autoantibodies reacting with vasopressin and oxytocin in relation to cortisol secretion in mild and moderate depression. Prog Neuropsychopharmacol Biol Psychiatry. 2011;35(1):118-25.

53. Ozsoy S, Esel E, Kula M. Serum oxytocin levels in patients with depression and the effects of gender and antidepressant treatment. Psychiatry Res. 2009;169(3):249-52.

54. Scantamburlo G, Hansenne M, Fuchs S, Pitchot W, Maréchal P, Pequeux C, et al. Plasma oxytocin levels and anxiety in patients with major depression Psychoneuroendocrinology. 2007;32(4):407-10.

55. Anderberg UM, Uvnäs-Moberg K. Plasma oxytocin levels in female fibromyalgia syndrome patients. Z Rheumatol. 2000;59(6):373-9.

56. Frasch A, Zetzsche T, Steiger A, Jirikowski GF. Reduction of plasma oxytocin levels in patients suffering from major depression. Adv Exp Med Biol. 1995;395:257-8

57. Zetzsche T, Frasch A, Jirikowski G, Murck H, Steiger A. Nocturnal oxytocin secretion is reduced in major depression [abstract 290]. Biol Psychiatry. 1996;39(7):584.

58. Demitrack MA, Gold PW. Oxytocin: neurobiologic considerations and their implications for affective illness. Prog Neuropsychopharmacol Biol Psychiatry. 1988;12(Suppl):S23-51.

59. Pitts AF, Samuelson SD, Meller WH, Bissette G, Nemeroff CB, Kathol RG Cerebrospinal fluid corticotropin-releasing hormone, vasopressin, and oxytocin concentrations in treated patients with major depression and controls. Biol Psychiatry. 1995;38(5):330-5.

60. Heim C, Young LJ, Newport DJ, Mletzko T, Miller AH, Nemeroff CB. Lower CSF oxytocin concentrations in women with a history of childhood abuse. Mol Psychiatry. 2009;14(10):954-8

61. Holt-Lunstad J, Birmingham W, Light KC. The influence of depressive symptomatology and perceived stress on plasma and salivary oxytocin before, during and after a support enhancement intervention. Psychoneuroendocrinology. 2011;36(8):1249-56.

62. Purba JS, Hoogendijk WJ, Hofman MA, Swaab DF. Increased number of vasopressin- and oxytocin-expressing neurons in the paraventricular nucleus of the hypothalamus in depression. Arch Gen Psychiatry. 1996:53(2):137-43.

63. Meynen G, Unmehopa UA, Hofman MA, Swaab DF, Hoogendijk WJ. Hypothalamic oxytocin mRNA expression and melancholic depression. Mol Psychiatry. 2007;12(2):118-9.

64. Wang SS, Kamphuis W, Huitinga I, Zhou JN, Swaab DF. Gene expression analysis in the human hypothalamus in depression by laser microdissection and real-time PCR: the presence of multiple receptor imbalances. Mol Psychiatry. 2008;13(8):786-99.

65. van Londen L, Goekoop JG, van Kempen GM, Frankhuijzen-Sierevogel AA, Wiegant VM, van der Velde EA, et al. Plasma levels of arginine vasopressin elevated in patients with major depression. Neuropsychopharmacology. 1997; 17(4):284-92

66. Cyranowski JM, Hofkens TL, Frank E, Seltman H, Cai HM, Amico JA. Evidence of dysregulated peripheral oxytocin release among depressed women. Psychosom Med. 2008;70(9):967-75

67. Yoshimoto S, Babygirija R, Dobner A, Ludwig K, Takahashi T. Anti-stress effects of transcutaneous electrical nerve stimulation (TENS) on colonic motility in rats. Dig Dis Sci. 2012;57(5):1213-21.

68. Yang YQ, Huang GY. Effect of acupuncture on Cx43 knock-out mice dysmenorrhea response [in Chinese]. Zhen Ci Yan Jiu. 2008;33(6):366-71.

69. Yang YQ, Huang GY. Study on effects of acupuncture on mice dysmenorrhea model and the mechanism [in Chinese]. Zhongguo Zhen Jiu. 2008;28(2):119-21.

70. Liu F, Zheng CH, Huang GY, Wang W. Influence of $\mathrm{Cx} 43$ on acupuncture effect on the primary dysmenorrheal rat [in Chinese]. Zhongguo Zhen Jiu. 2008;28(10):751-6.

71. Yang J, Yang Y, Chen JM, Liu WY, Wang CH, Lin BC. Effect of oxytocin on acupuncture analgesia in the rat. Neuropeptides. 2007;41(5):285-92.

72. Uvnäs-Moberg K, Bruzelius G, Alster P, Lundeberg T. The antinociceptive effect of non-noxious sensory stimulation is mediated partly through oxytocinergic mechanisms. Acta Physiol Scand. 1993;149(2):199-204.

73. Jun Y. Effect of acupuncture on the contents of vasopressin and oxytocin in the rat [in Chinese]. Zhen Ci Yan Jiu. 1992;17(3):217-20.

74. Zhang R, Jia MX, Zhang JS, Xu XJ, Shou XJ, Zhang XT, et al. Transcutaneous electrical acupoint stimulation in children with autism and its impact on plasma levels of arginine-vasopressin and oxytocin: a prospective single-blinded controlled study. Res Dev Disabil. 2012:33(4):1136-46.

75. Lei X, Liu W. Oxytocin and endogenous opioid peptide are synergistic during electroacupuncture analgesia: is it a synergistic action? [in Chinese]. Chin J Clin Rehabil. 2005;9(24):112-3.

76. Liu W, Song C, Wang C, Lin B. Effect of oxytocin and cholecystokinin octapeptide (CCK-8) on electroacupuncture (EA) analgesia [in Chinese]. Zhen Ci Yan Jiu. 1992;17(2):136-8.

77. Liu W, Song C, Yang J, Lin B, Wang C. Involvement of oxytocin in spinal cord in acupuncture analgesia [in Chinese]. Zhen Ci Yan Jiu. 1990;15(1):24-9.

78. Song CY, Liu WY, Gu XY, Lin BC. Effect of anti-opioid peptide sera on oxytocin-induced enhancement of electroacupuncture analgesia [in Chinese]. Sheng Li Xue Bao. 1993;45(3):231-6.

79. Song CY, Liu WY, Yang J, Lin BC, Zhu HN. The role of central oxytocin in electroacupuncture analgesia [in Chinese]. Sheng Li Xue Bao. 1990;42(2):169-74.

80. Aghamohammadi A, Behmanesh F, Zafari M, Tofighi M. Effect of using transcutaneous electrical nerve stimulation (TENS) in acupuncture points [Hegu (LI4) and Sanyinjiao (SP6)] on duration of the first stage of labor [in Arabic]. J Babol Univ Med Sci. 2011;13(2):19-24.

81. Gaudernack LC, Forbord S, Hole E. Acupuncture administered after spontaneous rupture of membranes at term significantly reduces the length of birth and use of oxytocin: a randomized controlled trial. Acta Obstet Gynecol Scand. 2006;85(11):1348-53.

82. Aghdam SK, Daryabakhsh A. Effect of acupressure at Hugo point (LI4) on the process and outcomes of labor in nulliparous women [in Persian]. Iranian J Obstet Gynecol Infertil. 2012;15(27):14-20.

83. Kashanian M, Shahali S. Effects of acupressure at the Sanyinjiao point (SP6) on the process of active phase of labor in nulliparas women. J Matern Fetal Neonatal Med. 2010;23(7):638-41.

84. Hantoushzadeh S, Alhusseini N, Lebaschi AH. The effects of acupuncture during labour on nulliparous women: a randomised controlled trial. Aust N Z J Obstet Gynaeocol. 2007;47(1):26-30.

85. Ziaei S, Hajipour L. Effect of acupuncture on labor. Int J Gynaecol Obstet. 2006;92(1):71-2. 
86. Skilnand E, Fossen D, Heiberg E. Acupuncture in the management of pain in labor. Acta Obstet Gynecol Scand. 2002;81(10):943-8.

87. Rabl M, Ahner R, Bitschnau M, Zeisler H, Husslein P. Acupuncture for cervical ripening and induction of labor at term - a randomized controlled trial. Wien Klin Wochenschr. 2001;113(23-24):942-6.

88. Zeisler H, Michaela R, Witt A, Husslein P. Increased fetal movements - a marker for successful prenatal treatment with acupuncture? Clin Acupunct Orient Med. 2001;2(4):206-8.

89. Fatemeh VR, Zahra S. The effects of TENS applying on specific acupuncture points versus thoracic-lumbosacral vertebras on active phase of labor. J Psychosom Obstet Gynaecol. 2010;31:125.

90. Liu J, Han Y, Zhang N, Wang B, Zhou Y, Yang D, et al. The safety of electroacupuncture at Hegu (LI 4) plus oxytocin for hastening uterine contraction of puerperants - a randomized controlled clinical observation. J Tradit Chin Med. 2008;28(3):163-7.

91. Ramnerö A, Hanson U, Kihlgren M. Acupuncture treatment during labour a randomised controlled trial. BJOG. 2002;109(6):637-44.

92. Lyrenäs S, Lutsch H, Hetta J, Lindberg B. Acupuncture before delivery: effect on labor. Gynecol Obstet Invest. 1987;24(4):217-24.

93. Zaslawski $\mathrm{C}$. The impact of ethics on the design and conduct of acupuncture clinical trials. Clin Acupunct Orient Med. 2003;4(4):121-6.

94. Cassidy CM. Chinese medicine users in the United States. Part I: utilization, satisfaction, medical plurality. J Altern Complement Med. 1998;4(1):17-27.

95. Fønnebø V, Grimsgaard S, Walach H, Ritenbaugh C, Norheim A, MacPherson H, et al. Researching complementary and alternative treatments - the gatekeepers are not at home. BMC Med Res Methodol. 2007;7:7

96. Witt C, Aickin M, Baca T, Cherkin D, Haan MN, Hammerschlag R, et al. Effectiveness Guidance Document (EGD) for acupuncture research - a consensus document for conducting trials. BMC Complement Altern Med. 2012;12:148.

97. MacPherson $\mathrm{H}$, Schroer $\mathrm{S}$. Acupuncture as a complex intervention for depression: a consensus method to develop a standardised treatment protocol for a randomised controlled trial. Complement Ther Med. 2007;15(2):92-100.

98. Schnyer RN, Allen JJB. Acupuncture in the treatment of depression: a manual for practice and research. London: Churchill Livingstone; 2001.

99. Birch S. Clinical research on acupuncture: part 2. Controlled clinical trials, an overview of their methods. J Altern Complement Med. 2004;10(3):481-98.

100. Schnyer RN, Iuliano D, Kay J, Shields M, Wayne P. Development of protocols for randomized sham-controlled trials of complex treatment interventions: Japanese acupuncture for endometriosis-related pelvic pain. J Altern Complement Med. 2008;14(5):515-22.

101. Witt CM. Clinical research on acupuncture - concepts and guidance on efficacy and effectiveness research. Chin J Integr Med. 2011;17(3):166-72.

102. Lindquist R, Wyman JF, Talley KM, Findorff MJ, Gross CR. Design of control group conditions in clinical trials of behavioral interventions. J Nurs Scholarsh. 2007:39(3):214-21.

103. Kaptchuk TJ. The placebo effect in alternative medicine: can the performance of a healing ritual have clinical significance? Ann Intern Med. 2002;136(11):817-25

104. Chan AW, Tetzlaff JM, Altman DG, Laupacis A, Gøtzsche PC, Krleža-Jerić K, et al. SPIRIT 2013 statement: defining standard protocol items for clinical trials. Ann Intern Med. 2013:158(3):200-7.

105. Chan AW, Tetzlaff JM, Gøtzsche PC, Altman DG, Mann H, Berlin JA, et al. SPIRIT 2013 explanation and elaboration: guidance for protocols of clinical trials. BMJ. 2013;346:e7586.

106. Cox JL, Holden JM, Sagovsky R. Detection of postnatal depression: development of the 10-item Edinburgh Postnatal Depression Scale. Br J Psychiatry. 1987;150(6):782-6.

107. Milgrom J, Schembri C, Ericksen J, Ross J, Gemmill AW. Towards parenthood: an antenatal intervention to reduce depression, anxiety and parenting difficulties. J Affect Disord. 2011;130(3):385-94.

108. NSW Government Health, South Western Sydney Local Health District. Campbelltown and Camden Hospitals operational plan 2014-2018. https:// www.swslhd.nsw.gov.au/pdfs/OP_Campbelltown.pdf. Accessed 3 Feb 2016.

109. NSW Government Health. South Western Sydney Local Health District year in review 2014/15. https://www.swslhd.nsw.gov.au/pdfs/2015_Review.pdf. Accessed 3 Feb 2016.

110. Furukawa TA, Kessler RC, Slade T, Andrews G. The performance of the K6 and K10 screening scales for psychological distress in the Australian National Survey of Mental Health and Well-Being. Psychol Med. 2003;33(2):357-62.

111. Selva Olid A, Martínez Zapata MJ, Solà I, Stojanovic Z, Uriona Tuma SM, Bonfill CX. Efficacy and safety of needle acupuncture for treating gynecologic and obstetric disorders: an overview. Med Acupunct. 2013; 25(6):386-97.

112. Park J, Sohn $Y$, White $A R$, Lee $H$. The safety of acupuncture during pregnancy: a systematic review. Acupunct Med. 2014;32(3):257-66.

113. MacPherson $\mathrm{H}$. Acupuncture research: time to shift from theoretical to practical questions. J Altern Complement Med. 2006;12(9):837-9.

114. Horowitz J. Acupuncture and emotional imbalance: the importance of awareness in treating the root. Med Acupunct. 2011;23(1):19-26.

115. O'Brien K, Birch S. Toyohari meridian therapy: a form of acupuncture that challenges our assumptions while opening new vistas for explorations of acupuncture. In: Saad M, editor. Acupuncture - clinical practice, particular techniques and special issues. Maastricht, the Netherlands: Institute for New Technologies; 2011. p. 99.

116. Maciocia G. The foundations of Chinese medicine: a comprehensive text for acupuncturists and herbalists. New York: Churchill Livingstone; 1989.

117. Deadman P, Al-Khafaji M, Baker K. A manual of acupuncture. Hove, UK: Journal of Chinese Medicine Publications; 1998.

118. Maciocia G. The channels of acupuncture: clinical use of the secondary channels and eight extraordinary vessels. Philadelphia: Churchill Livingstone; 2006.

119. Manaka Y, Itaya K, Birch S. Chasing the dragon's tail: the theory and practice of acupuncture in the work of Yoshio Manaka. Paradigm: Brookline, MA; 1995.

120. Albertson K. Acupuncture and Chinese herbal medicine for women's health: bridging the gap between Western and Eastern Medicine. North Charleston, SC: CreateSpace; 2009.

121. Low RH. The secondary vessels of acupuncture: a detailed account of their energies, meridians and control points. Wellingborough, UK: Thorsons; 1983.

122. Birch S, Ida J. Japanese acupuncture: a clinical guide. Brookline, MA: Paradigm; 1998.

123. Wang L, Zhang J. Acupuncture and moxibustion for depression: a clinical series. Shelton, CT: People's Medical Publishing House; 2010.

124. Ellis AW, Wiseman N, Boss K. Grasping the wind: an exploration into the meaning of Chinese acupuncture point names. Brookline, MA: Paradigm; 1989.

125. Kendall-Tackett K. Four research findings that will change what we think about perinatal depression. J Perinat Educ. 2010;19(4):7-9.

126. Betts D. Inducing labour with acupuncture - crucial considerations. J Chin Med. 2009;90:20-5.

127. Wayne PM, Kerr CE, Schnyer RN, Legedza AT, Savetsky-German J, Shields $\mathrm{MH}$, et al. Japanese-style acupuncture for endometriosis-related pelvic pain in adolescents and young women: results of a randomized sham-controlled trial. J Pediatr Adolesc Gynecol. 2008;21(5):247-57.

128. Smith CA, Hay PP, MacPherson H. Acupuncture for depression. Cochrane Database Syst Rev. 2010;1:CD004046.

129. Zhang ZJ, Chen HY, Yip KC, Ng R, Wong VT. The effectiveness and safety of acupuncture therapy in depressive disorders: systematic review and meta-analysis. J Affect Disord. 2010;124(1-2):9-21.

130. Nahas $R$, Sheikh O. Complementary and alternative medicine for the treatment of major depressive disorder. Can Fam Physician. 2011;57(6):659-63.

131. Wenbin E. Clinical research on acupuncture treatment of depressive psychosis. World J Acupunct Moxibustion. 2002;12(3):13-6.

132. Cheng $Y$, Tang Q. Abdominal acupuncture in treating liver-qi stagnation and spleen deficiency in the elderly with post-stroke depression: a randomized and controlled observation. Chin J Clin Rehabil Tissue Eng Res. 2007;11(39):7791-4.

133. Huang Y, Xia DB. Clinical observation on treatment of depression with scalp electro-acupuncture: a report of 30 cases [in Chinese]. Zhong Xi Yi Jie He Xue Bao. 2004;2(2):151.

134. Matsumoto K, Euler D. Kiiko Matsumoto's clinical strategies: in the spirit of Master Nagano, vol. 1. Newton Highlands, MA: Kiiko Matsumoto International; 2002.

135. Matsumoto K, Euler D. Kiiko Matsumoto's clinical strategies: in the spirit of Master Nagano, vol. 2. 1st ed. Newton Highlands, MA: Kiiko Matsumoto International; 2008.

136. Finston P. Extraordinary meridian treatment for severe mental disorders plus augmentation with psychotherapy, Indian Raga music, and essential oils. Med Acupunct. 2009;21(1):27-34.

137. Smith C, Hancock H, Blake-Mortimer J, Eckert K. A randomised comparative trial of yoga and relaxation to reduce stress and anxiety. Complement Ther Med. 2007;15(2):77-83.

138. Eberhard-Gran M, Eskild A, Tambs K, Opjordsmoen S, Samuelsen SO. Review of validation studies of the Edinburgh Postnatal Depression Scale. Acta Psychiatr Scand. 2001;104(4):243-9. 
139. Lovibond PF, Lovibond SH. The manual for the depression anxiety stress scales. Sydney, Australia: Psychology Foundation of Australia; 1995.

140. The WHOQOL Group. Development of the World Health Organization WHOQOL-BREF quality of life assessment. Psychol Med. 1998;28(3):551-8.

141. Brown TA, Chorpita BF, Korotitsch W, Barlow DH. Psychometric properties of the Depression Anxiety Stress Scales (DASS) in clinical samples. Behav Res Ther. 1997;35(1):79-89.

142. Oei TP, Sawang S, Goh YW, Mukhtar F. Using the Depression Anxiety Stress Scale 21 (DASS-21) across cultures. Int J Psychol. 2013;48(6):1018-29.

143. Matthey S. Assessing the experience of motherhood: the Being a Mother Scale (BaM-13). J Affect Disord. 2011;128(1-2):142-52.

144. Allen JJB, Schnyer RN, Hitt SK. The efficacy of acupuncture in the treatment of major depression in women. Psychol Sci. 1998;9(5):397-401.

145. Newell DJ. Intention-to-treat analysis: implications for quantitative and qualitative research. Int J Epidemiol. 1992;21(5):837-41.

146. MacPherson H, Altman DG, Hammerschlag R, Youping L, Taixiang W, White A, et al. Revised STandards for Reporting Interventions in Clinical Trials of Acupuncture (STRICTA): extending the CONSORT Statement. Med Acupunct. 2010;22(3):167-80.

147. Rogers $C$, Rogers $C$. Point location and point dynamics manual. 3rd ed. Sydney, Australia: Acupuncture Colleges (Australia); 1989

\section{Submit your next manuscript to BioMed Central} and we will help you at every step:

- We accept pre-submission inquiries

- Our selector tool helps you to find the most relevant journal

- We provide round the clock customer support

- Convenient online submission

- Thorough peer review

- Inclusion in PubMed and all major indexing services

- Maximum visibility for your research

Submit your manuscript at www.biomedcentral.com/submit 